\title{
A Química e a Humanidade *
}

\begin{abstract}
"All Science is a very, human entreprise, coloured by our general ideas, changeable as any human activity must be, various in its possible forms, and a common part of the lives of all men."
\end{abstract}

Warren Weaver

Uma breve exposição deste tema não poderá deixar de ser necessariamente limitativa e essencialmente generalista. Ao procurar essas limitações, haverá uma tendência imediata, ou para realçar dominantemente os aspectos da Química, correndo o risco de não se ultrapassar o domínio da divulgação científica e tecnológica, redundante para esta audiência, ou então para se dar uma maior ênfase aos aspectos humanos, na sua interligação como a Química, podendo assim tender-se para um domínio que ultrapassa o âmbito e os propósitos desta Associação.

Para obviar a esses extremos, mas sem os ignorar, limitamo-nos a apresentar alguns aspectos concretos onde a influência da Química na vida intelectual e material do Homem, é já uma realidade. O conhecimento da estrutura da matéria e a produção de bens assim como outros que, poderão vir a ter um impacto mais significativo na Humanidade - o desenvolvimento da Química nos processos dos organismos vivos e as ameaças que a própria Química pode apresentar para a vida.

O interesse da Química para o homem reside, essencialmente, na sua imensa importância prática. É através das análises e das sínteses que a Química consegue identificar e obter as diversas substâncias. Foi também através de processos de análise e síntese intelectivas que a Ciência Química se afirmou e se desenvolveu.

$\mathrm{O}$ interesse futuro da Química continuará a orientar-se dominantemente para a transformação e o controlo da Natureza pelo próprio homem, mas necessitará no seu processo evolutivo, de recorrer a novos aspectos do conhecimento dessa mesma Natureza, que lhe terão de ser transferidos e comunicados por outras c i ê n c i a s, como a Física, a Biologia e a Ciência do Ambiente.

Novas variáveis terão assim de ser contempladas e, consequentemente, sistemas mais complexos terão de ser abordados. Novas teorias e novas concepçð̃es terão de ser elaboradas, que transcendam as existentes, e que permitem, por uma atitude de espírito indutiva e dedutiva, abrangendo as diversas dimensōes, encontrar, por parte do cientista, do técnico e do próprio cidadão, o progresso cadenciado e equilibrado da Química que melhor sirva a Humanidade, libertando-a simultaneamente das influências que poderão ameaçar a sua destruição.

II

A imensa variedade de substâncias que constituem o mundo físico interfere e condiciona necessariamente, em muitos aspectos, a vida da Humanidade.

A transformação dessas substâncias operou-se através dos tempos, por condicionalismos das próprias forças da Natureza. Só ao fim de muitos e muitos anos, mercê de uma aplicação sistemática e progressiva de experimentações e raciocínios científicos, essas transformações vieram, progressivamente, a ser determinadas e controladas pelo próprio homem, no interesse da sua vida e na orientação das suas necessidades.

Os organismos vivos são eles próprios também constituídos por uma variedade de substâncias, onde, constantemente, se operam transformações que determinam a vida ou morte, e até o seu próprio comportamento.

O conhecimento e o controlo de todas essas transformaçōes tem ocupado e continuará a ocupar o trabalho fundamental, árduo e fascinante, da Ciência Química e da arte da Química, entendida hoje, mais propriamente, como a indústria química.

Uma das primeiras dúvidas, de natureza química, que se apresentou ao homem, foi o conhecimento da estrutura da matéria que constitui o Universo físico e das mutações dessa mesma matéria. Perante a complexidade e variedade do mundo físico e das substâncias que o constituem, o espírito humano teve, naturalmente, uma dificuldade imediata de apreensão e compreensão das identidades e interligações dos diversos elementos dessa realidade, bem como das causas e processos que determinam e caracterizam as suas evoluções e transformações.

São, na realidade, mais imediatamente apreensiveis pelo entendimento humano, os fenómenos em que intervém um número limitado de variáveis. São exemplo disso os fenómenos físicos que se exprimem, de forma clara, por um modo distinto de pensamento permitido pela ciência matemática, como são por exemplo a lei de Ohm da electricidade e a lei de Hook da deformação elástica. Dum modo geral, aí se situam, nesse sentido de apreensão mais imediata todos os fenómenos da Física, hoje designada por clássica, onde não intervêm escalas de espaço e de tempo infinitas relati-

\footnotetext{
* Comunicação apresentada no painel: Química para Químicos e Química para cidadãos, 8. ${ }^{\circ}$ Encontro Anual da Sociedade Portuguesa de Quimica, Braga, Abril de 1985.
}

a Petrogal, Direcção-Geral de Produtos Químicos. 
vamente à dimensão da sensibilidade dos órgãos humanos de percepção.

O conhecimento actual e verdadeiramente científico da estrutura química da matéria e da sua transformação, data de há pouco mais de cem anos. Foi, essencialmente, o trabalho das três gerações que nos precederam:

- que conseguiu inventariar, classificar e sistematizar o conhecimento das diversas substâncias existentes na Natureza e a sua estrutura;

- que veio descobrindo progressivamente as simplificaçð̃es que estão subjacentes a todos os sistemas complexos, como é o facto, hoje nada surpreendente para qualquer estudante de química, de que as diversas substâncias que existem ou que poderão ser produzidas, resultam da agregação e ordenação de um número limitado de átomos - menos de uma centena!

- que veio, progressivamente, estabelecendo, atrąvés de raciocínios indutivos, da criatividade de concepções e da sua verificação experimental e dedutiva, as leis e os princípios científicos dos fenómenos e das transformaçōes químicas, sem os quais, o espirito humano se veria impossibilitado de desenvolver um trabalho sistematizado, rápido e seguro, e orientado, progressivamente, para objectivos mais definidos.

Sem procurar ser exaustivo na enumeração dos factos mais singulares e das pessoas que, durante as três últimas gerações, mais contribuiram para o conhecimento científico das estruturas e das transformações químicas, não poderemos deixar de apontar alguns exemplos mais representativos pela forma de trabalho intelectual e humano que lhes são inerentes.

Assim, o trabalho de Mendelief nos anos 70 do século passado, congregou uma simplificação e arrumação notáveis dos elementos da matéria. Foi conseguido por uma persistente análise e indução, e permitiu, simultaneamente, deduções lógicas e mais imediatas, que levaram à descoberta de novos elementos até então desconhecidos. Para além disso, a expressão assim simplificada e inteligivel da realidade exterior, possibilitou a caracterização de várias propriedades qualitativas, por uma correspondência dos valores quantitativos, identificados pelos números de ordem seriados na arrumação lógica do quadro que desenvolveu, e que hoje constitui uma ferramenta básica do ensino e compreensão da Química.

A descoberta do electrão por Thompson nos finais do século passado, que, iniciando o caminho dos desenvolvimentos da física atómica e nuclear, que se processou nos princípios do século, permitiu romper e ultrapassar as concepções milenárias reinantes da indivisibilidade do átomo.

As teorias atómicas de Rutherford e Bohr, que nessa consequência se desenvolveram, vieram permitir à Ciência Química estabelecer novas concepçổes da ligação química dos elementos, que, distinguindo-se e transcendendo as anteriores, potenciaram, por essa razão, deduções e descobertas mais imediatas na área das transformaçðes químicas.

Todas estas citaçōes são aqui referenciadas como exemplo de qualidade e atitudes humanas e de metodologia de trabalho que caracterizam o comportamento científico, e que terão de concorrer, em simultâneo, para que o homem possa apreender e ultrapassar a compreensão e orientação dos fenómenos da Natureza, no sentido de uma utilização adequada para melhor satisfação da sua vida.

Podem ser consideradas excepcionais as qualidades de inspiração e inteligência indutiva que levam à generalização das interpretações e das leis científicas, a maior parte das vezes leis de probabilidades e não de certezas, e por isso efémeras e insuficientes. Mas são absolutamente normais e comuns à maioria dos cidadãos, as outras qualidades e atitudes complementares - como a determinação, a dúvida, a persistência, o desenvolvimento progressivo e metódico de toda a experiência acumulada - que, constituindo os aspectos dominantes e seguros do comportamento científico, permitem a qualquer indivíduo a resolução prática dos grandes e pequenos problemas que tem de enfrentar, e o seu posicionamento e intervenção, perante os fenómenos da Química do Universo.

\section{III}

Na sua vida diária, os cidadãos estão cada vez mais dependentes dos produtos que se originaram através das transformações permitidas pela Química.

Quer se trate das suas necessidades básicas e essenciais, ou de um conforto e bem-estar mais exigentes, a Humanidade utiliza constantemente:

- os materiais mais diversos obtidos dos produtos naturais por processos quimicos, ou aqueles que são inteiramente fabricados por síntese, e que são utilizados, quer nos edifícios e abrigos que constituem o envolvimento habitacional das populaçōes, quer no vestuário que utiliza para se resguardar, quer nos veículos que necessita para as suas deslocações, quer ainda nos suportes e meios físicos utilizados nos diversos processos de comunicação;

- os produtos químicos que asseguram a produção dos alimentos que necessita - os adubos e pesticidas;

- os diversos produtos de consumo que permitem preservar a saúde e a higiene;

- os combustíveis - obtidos também por transformações químicas - necessários aos diversos processos de aquecimento e iluminação, à movimentação dos veículos de transporte e ao accionamento das diversas máquinas e mecanismos, nas mais diversas escalas, e para os mais distintos fins;

- uma diversidade crescente de produtos e formulações (desde colas e aditivos a catalisadores, produtos de acabamento, preservantes, etc.), que condicionam ou estimulam os mais diversos aspectos funcionais requeridos ao nível do consumo ou da produção.

No entanto, o conhecimento e a consciencialização destas realidades apenas focalizam os aspectos mais directos e mais imediatos e, de certa forma, mais secundários, daquilo que a Química, nos seus esfeitos práticos, tem posto à disposição do homem e do enriquecimento da sua vida.

A montante de todos esses produtos enunciados, e que maior contacto directo têm com as populações, desenvolve-se todo um conjunto de transformaçð̄es químicas primárias de que o utilizador final se não apercebe imediatamente, que constituem os marcos fundamentais, que permitiram desenvolver e estruturar, toda uma indústria química, que se ramifica numa di- 
versidade de produçð̄es e de aplicaçōes e se interliga numa série sequenciada de operações.

Durante os últimos cem anos o desenvolvimento de novos processos e novas produçð̃es quimicas foi enorme. São de salientar, por exemplo, os principais produtos de síntese (plásticos, fibras sintéticas, produtos farmacêuticos e pesticidas), cuja inovação ocorreu basicamente, no periodo que se iniciou pouco antes da 2. ' Guerra Mundial até ao post-guerra. A expansão económica que caracterizou as décadas de 60 e 70 veio aproveitar toda esta inovação para uma produção industrial em massa.

A crise económica dos últimos anos, o aumento de preço da energia e das matérias-primas energéticas, bem como a ausência de inovações químicas relevantes durante as últimas três décadas, têm forçado a indústia a adaptar-se a novas configurações.

Continuam a existir populaçōes carecidas de inúmeros bens, que só lhe poderão ser proporcionados pela indústria química, tal como hoje se situa, ao nivel das suas potencialidades científicas e tecnológicas.

No entanto, as mutações que se detectam, apontam dominantemente, sem que se altere a realidade das situações existentes, que terão de ser realinhadas e adaptar-se a um crescimento mais lento, para o desenvolvimento de novos processos e para uma química substancialmente distinta, como será, por exemplo, a bioquímica.

\section{IV}

As investigações que ocorreram no domínio da Biologia desde o início deste século, e sobretudo nos anos 50 , transformaram completamente a nossa maneira de pensar sobre o mundo vivo.

Disciplinas que até então eram estudadas e desenvolvidas separadamente, como a físiologia celular, a genética, a bioquímica, a microbiologia, a virologia, fundiram-se numa disciplina comum - a biologia molecular.

A partir dela se procura, por uma visão mais generalizada dos fenómenos e das leis que eles permitem induzir, explorar as propriedades e os comportamentos dos seres vivos, pela estrutura e interacção das moléculas que os compõem.

O conhecimento da estrutura das principais macromoléculas biológicas - proteínas e ácidos nucleicos a interpretação das suas funções em consequência das suas estruturas, o reconhecimento das suas vias de biosintese, permitiu modificar completamente os nossos conhecimentos sobre a hereditariedade e os mecanismos celulares. $\mathrm{O}$ funcionamento da célula assemelha-se verdadeiramente ao de uma indústria química miniaturizada e automatizada, com uma eficiência que desafia os nossos próprios meios tecnológicos.

$\mathrm{O}$ interesse recente que as instituições de ensino, de investigação e económicas, têm anunciado relativamente às ciências da vida e às biotecnologias, permitẹ-nos aperceber, que importantes inovações poderão vir a ocorrer nestes domínios, quer ao nível da investigação fundamental ou aplicada. Nessa linha de desenvolvimento surgirá naturalmente, com marcada prioridade, o homem, como objecto de estudo para o próprio homem, esperando-se que sejam abordados de uma nova maneira assuntos tão complexos como o funcionamento do cérebro, as dificiências genéticas e toda uma gama de doenças.

Para além disso, são também os campos da própria indústria, da saúde pública, da farmacologia, da nutrição e da agronomia, que se preparam para se adaptarem e responderem aos desenvolvimentos permitidos por essas inovaç̃es.

\section{$\mathbf{V}$}

A melhoria da qualidade e do nível de vida que se tem verificado nos últimos decénios nas regiōes industrializadas é devida, em grande parte, ao incremento de consumo de produtos químicos e ao aumento da sua variedade, que a própria indústria tem disponibilizado, para beneficiar a agricultura, a saúde, a qualidade dos alimentos e, de uma maneira geral, a maioria dos produtos do consumo industrial e doméstico.

No entanto, a utilização e a produção maciça desses produtos, e também, dum modo geral, a concentração industrial exigida pelo desenvolvimento económico, começou já a acusar os seus riscos e os seus custos, pelas ameaças que tem apresentado para a saúde e segurança das populações e para a deterioração do meio ecológico.

O recente acidente de Bophal, com uma fuga de metilisocianato numa fábrica de pesticidas, que dizimou milhares de pessoas, alertou seriamente a opinião pública mundial e a própria indústria química.

São também muito recentes as divulgações que têm sido publicitadas sobre a destruição de florestas na Alemanha, como resultado da poluição, originada de zonas fortemente industrializadas, bem como acidentes e destruições várias, mais localizadas ou mais expandidas, que constantemente se têm verificado ou detectado nos últimos anos.

As instituições que, a nível nacional ou internacional, se ocupam do estabelecimento e fiscalização dos níveis de segurança e de poluição, intervêm muitas vezes "a posteriori», na sequência dos acidentes ocorridos, e quando impõem regulamentos apriorísticos, eles são algumas das vezes estabelecidos, em dissonância com as realidade e com as possibilidades concretas dos sistemas.

Não queremos com isto significar, que os desequilibrios temporais, num sentido ou noutro, permitidos por estè desajustamentos, invalidem a justificação ou a necessidade deste tipo de intervençðes, mas apenas que ele não é suficiente, e que são necessárias outras actuações e outras concepções, e que não sejam descuradas as metodologias que, através dos tempos, permitiram todo o desenvolvimento científico e o entendimento do homem e da Natureza pelo espírito humano.

O progresso e a evolução que ao longo dos milénios a Natureza imprimiu à sua própria matéria e à formação e desenvolvimento dos organismos vivos, foi um processo prosseguido por etapas sucessivas, envolvendo estabilidades intermediárias dos sistemas que, progressivamente, se foram tornando mais complexos.

Os átomos originaram moléculas, estas formaram bases que dirigiram a formação de amino-ácidos, que por sua vez formaram proteinas, e que evoluíram para a formação de células, progredindo assim, sucessivamente, etapa por etapa, cada uma delas estável, até que se formaram os seres mais simples e os mais complexos que hoje habitam o Universo.

As colisర̃es nucleares que se processam nas estrelas vão originando a formação de elementos progressivamente mais pesados. A colisão de dois núcleos de hidrogénio pesado origina, por fusão, um núcleo de hélio; a colisão de 3 núcleos de hélio resulta num 
núcleo de carbono, e assim progressivamente. Para além de uma certa dimensão, quando os elementos se tornam maiores e mais complexos, tendem a desintegrar-se num processo potencialmente explosivo.

Também o progresso e a evolução que o homem desenvolve na própria Natureza não pode deixar de atender aos mesmos princípios.

A probabilidade de estados desordenados, que Boltzman caracterizou na sua equação da entropia, aumenta com a complexidade dos sistemas; e as confi- gurações mais elevadas só se originam a partir das unidades, estabilizadas, dos níveis inferiores.

No seu desafio constante para alterar a evolução normal da Natureza em seu proveito, não pode o homem alhear-se da responsabilidade que lhe cabe, de procurar, também, com a sua intervenção, e não apenas dos cientistas, mas de todo o cidadão comum, os estados estáveis e ordenados dos sistemas progressivamente mais complexos que vai criando, e que o seu desejo e determinação de progresso lhe impõem.

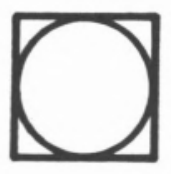

\section{DINAMISMO - QUALIDADE - SERVIÇO}

\section{ESCOLHA - EFICIÊNCIA}

PEÇA-NOS A LISTA DAS NOSSAS REPRESENTADAS

ALGUMA LHE INTERESSARÁ!

Estamos à distância do seu telefone... 